\title{
Precarious encounter with Paraganglioma during cystoscopic excisional biopsy of urinary bladder tumour
}

\author{
VN Gadre I* $^{*}$ \\ Associate Professor ${ }^{l}$, Department of Anesthesiology, B. J. Government Medical College, Pune, India.
}

\begin{abstract}
Tumours secreting catecholamine are a known perioperative anaesthetic challenge. However, extra adrenal location of such tumors can cause sudden catastrophe in unprepared patients.

A 45 year old, $50 \mathrm{~kg}$ female patient scheduled for transurethral cystoscopic resection of bladder tumour of suspected neoplastic aetiology, developed sudden, severe tachycardia, hypertension, and arrhythmias followed by hypotension under general anaesthesia. Tumour biopsy obtained during first surgery confirmed diagnosis of Paraganglioma (PGL). This was supported with normal vanillyl mandelic acid (VMA), $6.5 \mathrm{mg} / 24 \mathrm{hrs}$ (normal $2-8 \mathrm{mg} / 24 \mathrm{hrs}$ ) and a large polypoidal mass on CT in a patient with episodic symptoms of headache and blackout associated with micturition; a classical triad reported about this tumour category. Findings of MIBG (Meta iodo benzyl guanidine) ${ }^{131}$ I scan that reported no MIBG avid disease, were equivocal.

Accurate diagnosis, good perioperative control of blood pressure and volume status using invasive monitoring and cascade of drugs to manipulate circulation when required, formed the essence of successful management of the patient during her second surgery.
\end{abstract}

Keywords: Paraganglioma; pheochromocytoma; anaesthetic challenges

\section{Introduction}

Pheochromocytoma (PCC) is a tumour arising from chromaffin cells of adrenal medulla and secreting one or more catecholamines, adrenaline, noradrenaline and dopamine. A paraganglioma (PGL) is derived from extra adrenal chromaffin cells of sympathetic paravertebral ganglia of thorax, abdomen and pelvis; and also from parasympathetic ganglia of glossopharyngeal and vagus nerves. About $80-85 \%$ are PCC and $15-20 \%$ PGL. Generally being biochemically silent, PGLs produce paroxysmal symptoms. ${ }^{1}$

We present a case of cystoscopic biopsy and later excision of bladder tumour, not suspected to be a PGL before surgical biopsy.

*Correspondence: VN Gadre

E mail: vaijayantigadre@hotmail.com

Received: 09/01/2017

Accepted: 17/04/2017

DOI: 10.4038 /slja.v25i2.8203

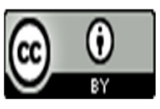

It was an unprepared case and the patient went into ventricular tachycardia and life threatening severe hypertension, arrhythmias and hypotension while under general anaesthesia for the biopsy.

\section{Case report}

A $45 \mathrm{yr}$ old $50 \mathrm{~kg}$ female with complaints of burning micturition, two episodes of haematuria associated with sweating, headache and black out since last six months, was scheduled for cystoscopy and biopsy. She had no significant medical history. She has had a tubectomy in the past. The findings on general and systemic examination were normal. ECG, x-ray chest and blood investigations were within normal limits. USG abdomen showed a $3.7 \times 2.8 \mathrm{~cm}$ echogenic polypoidal mass lesion arising from posterior bladder wall near right ureterovesical junction with significant vascularity on color Doppler, diagnosed therefore as of neoplastic aetiology. CT abdomen showed moderately enhancing polypoidal lesion on postero-lateral bladder wall.

Patient was subjected to general anaesthesia with informed risk of suspected malignancy. After preoxygenation with $100 \%$ oxygen and premedication with i.v. glycopyrrolate $5 \mu \mathrm{g} / \mathrm{kg}$, ondansetron $0.08 \mathrm{mg} / \mathrm{kg}$, midazolam $0.03 \mathrm{mg} / \mathrm{kg}$ and pentazocin $0.3 \mathrm{mg} / \mathrm{kg}$, patient was induced with 
thiopentone $5 \mathrm{mg} / \mathrm{kg}$, suxamethonium $1.5 \mathrm{mg} / \mathrm{kg}$. Endotracheal intubation was done under direct laryngoscopy with $7.5 \mathrm{~mm}$ cuffed oral tube and vecuronium $0.2 \mathrm{mg} / \mathrm{kg}$ was given for neuromuscular block and with $\mathrm{O}_{2}: \mathrm{N}_{2} \mathrm{O}$ 50:50 and isoflurane 1$1.5 \%$ for maintenance. ECG, $\mathrm{SpO}_{2}, \mathrm{EtCO}_{2}, \mathrm{NIBP}$ and skin temperature were monitored intra operatively.

During tumour manipulation for biopsy patient developed tachycardia (heart rate $130 / \mathrm{min} \rightarrow$ $180 / \mathrm{min} \rightarrow 200 / \mathrm{min}$.) and BP increased from 130/80 to $180 / 110$ and $210 / 120 \mathrm{mmHg}$. ECG showed ventricular tachycardia. Intravenous lignocaine $60 \mathrm{mg}$ was given. Surgeon was informed to stop for DC shock to be delivered. As soon as manipulation was stopped, ECG showed sinus rhythm and the systolic BP became $50 \mathrm{mmHg}$. BP was restored with intravenous fluids, procedure was abandoned after biopsy and patient was shifted to ICU for monitoring.

Postoperative ECG showed ST depression and inferolateral T-inversions. Findings of 2D ECHO showed concentric LVH, posterobasal hypokinesia, mild TR/MR, PAH 42mmHg with ejection fraction $50 \%$. Biopsy report confirmed paraganglioma and urinary VMA was 6.5mg/24hours (2$8 \mathrm{mg} / 24$ hours). MIBG ${ }^{131} \mathrm{I}$ scan reported no MIBG avid disease.

Patient was discharged on oral phenoxybenzamine $10 \mathrm{mg}$ BD for two weeks; it was discontinued 48 hours prior to surgery for PGL excision and oral labetalol 50mg OD was added for one week. Patient informed that her previous feelings of doom and fear had now subsided.

After recording baseline vitals and slow preloading, i.v. fentanyl $60 \mu \mathrm{g}$ was given. Observing closely, general anaesthesia was administered using thiopentone $5 \mathrm{mg} / \mathrm{kg}$, suxamethonium $1.5 \mathrm{mg} / \mathrm{kg}$ for induction, after pre-oxygenation with $100 \%$ oxygen and pre-medication with glycopyrrolate $5 \mu \mathrm{g} / \mathrm{kg}$, ondansetron $0.08 \mathrm{mg} / \mathrm{kg}$ and midazolam $0.03 \mathrm{mg} / \mathrm{kg}$. Vecuronium $0.2 \mathrm{mg} / \mathrm{kg}$ was given for neuromuscular block and $\mathrm{O}_{2}: \mathrm{N}_{2} \mathrm{O} 50: 50$ and isoflurane $1-1.5 \%$ was used for maintenance. Arterial line was inserted and right internal jugular vein was cannulated using $16 \mathrm{~F}$ triple lumen cannula. CVP was monitored and vasopressors, dopamine $(0.1-0.3 \mu \mathrm{g} / \mathrm{kg} / \mathrm{min})$ and noradrenaline $(0.02-0.1 \mu \mathrm{g} / \mathrm{kg} / \mathrm{min})$ were kept ready at second port and vasodilators sodium nitroprusside $(0.5 \mu \mathrm{g} / \mathrm{kg} / \mathrm{min})$ and nitroglycerine $(0.5 \mu \mathrm{g} / \mathrm{kg} / \mathrm{min})$ through the third port. Prompt titration and control of haemodynamics following sudden changes in HR and BP was to be achieved during induction, intubation, surgical handling, and dissection and anticipated sudden fall after removal.

Induction and intubation were uneventful. Clonidine $25 \mu \mathrm{g}$ with $1 \%$ lignocaine $3 \mathrm{ml}$ were given through lumbar epidural catheter placed for intra and postoperative analgesia. Surgical approach was infra-umbilical right para-median incision. Surgical plan was to perform partial or radicle cystectomy if invasion of muscle layer was evident. During the dissection and handling for removal of the tumour, blood pressure fluctuated frequently (130/80 to $190 / 100 \mathrm{mmHg}$ ) over a period of $45 \mathrm{mins}$ and was controlled using vasodilators and small dose of clonidine $20 \mu \mathrm{g}$ i.v.). A globular, fleshy, $3 \times 3 \mathrm{~cm}$, highly vascular mass weighing $50 \mathrm{gm}$ was removed from posterior wall of right UV junction. Blood pressure fall that was recorded up to $90 / 70 \mathrm{mmHg}$ was restored by intravenous fluids and small intermittent bolus doses of vasoconstrictors. Intraoperative record of blood sugar ranged between $95-145 \mathrm{mg} \%$. Patient was monitored in ICU for 24 hours after reversal and extubation. There were no signs of somnolence; intermittent epidural doses of $4 \mathrm{ml}$ of $0.25 \%$ bupivacaine were well tolerated and blood sugar values recorded ranged between $70-85 \mathrm{mg} \%$.

\section{Discussion}

The first published comprehensive review of data derived from US population based studies indicates the overall incidence of PCC to be 0.8lakhs /year. ${ }^{2}$

Fifty percent cases are diagnosed postmortem; and those at the time of incidental surgery precipitate hypertensive crises resulting in $80 \%$ mortality. ${ }^{3}$ PCCs that are extra adrenal and located commonly at aortic region, inferior renal poles are termed as PGLs.

Manipulation of such tumours causes significant increase in blood pressure, cardiac output and only moderate increase in systemic vascular resistance. 
Noradrenaline secreting tumours increase BP, systemic vascular resistance and decrease cardiac output. ${ }^{4}$

Our patient was diagnosed as urinary bladder tumour with high vascularity on USG and likely malignant aetiology from CT scan. She had normal ECG preoperatively and had developed infero lateral ischaemia due to sudden severe variations in blood pressure during biopsy; postoperative 2D ECHO supported the evidence.

She had a history of burning micturition and episodes of haematuria twice which were followed by sudden headache, giddiness and blackout. VMA values were normal and histopathology confirmed paraganglioma.

Paragangliomas are known for paroxysmal signs and symptoms, provoked only after use of medications with after effects. It is important to suspect, confirm, localize and treat by resecting such tumours for the danger of malignant transformation and hypersecretion of catecholamines. If left untreated, cardiovascular morbidity and mortality are high. ${ }^{5}$

Lack of catecholamine hypersecretion poses a significant diagnostic challenge, due to the absence of typical symptoms of catecholamine excess. The diagnosis is delayed until an advanced stage contributing to the development of malignant disease. Patients usually present with advanced disease and atypical symptoms caused by tumour mass effects rather than catecholamine excess.

For confirmatory diagnosis of PGLs plasma free metanephrine levels are better indicators than urinary metanephrines or VMA. ${ }^{6}$ Blood sampling should be done after overnight fasting; medications like alpha methyldopa, labetalol should be withdrawn $48 \mathrm{hrs}$ prior to testing to avoid falsely elevated results due to interference of these drugs with disposition of catecholamines. ${ }^{7} \mathrm{CT}$ with contrast form an excellent initial method to locate abdominal PGLs 5mm or larger; USG is suboptimal and ${ }^{131} \mathrm{I}$ MIBG is better recommended than ${ }^{123} \mathrm{I}$ in patients with normal adrenal glands because more uptake of latter misinterprets the results. ${ }^{5}$

Preoperative preparation with alpha blockade for 714 days is recommended. Adequate time is provided for BP to normalize and high sodium diet with fluid intake reverses catecholamine induced blood volume contraction thus avoiding hypotension after tumour removal. Stringent monitoring of HR, BP and blood sugar is mandatory during preparation. $^{5}$ Phenoxybenzamine blocks the receptors noncompetitively thus avoiding drug displacement from alpha adrenoceptors by excessive release of catecholamines during surgery. However extensive non-competitive blockade can result in postoperative hypotension, therefore pretreatment with prazocin is also recommended. ${ }^{1}$

Use of beta blockade before surgery improves cardiac outcome by preventing catecholamine surges and intraoperative arrhythmias. Its use should be avoided in patients with cardiomegaly and cardiomyopathy. ${ }^{8}$ Labetalol with $\alpha: \beta, 1: 5$ antagonistic activity is used for control of tachycardia, but not as an initial therapy before $\alpha$ blockade. $^{1}$

Anaesthesia management has been a formidable challenge including risks of catecholamine secretion similar to that in PCC, delayed gastric emptying and massive blood loss. Inadequate preoperative preparation, difficult surgical dissection with the resultant excessive release of different catecholamine is known to cause complications. After confirmatory diagnosis and adequate preparation, again general anaesthesia combined with an epidural was administered. Radicle / partial cystectomy with ileal conduit in case of malignant invasion necessitated good exposure and relaxation during surgery; tumour manipulation was expected to be performed gently. Epidural clonidine was expected to enhance analgesia along with inhibitory action on neurally mediated catecholamine release.

The postoperative complications are hypotension and hypoglycemia due to sudden withdrawal of excessive catecholamines from circulation and excessive rebound release of insulin. Postoperative follow up protocol includes annual cystoscopy, plasma and urine catecholamine analysis and MIBG scan.

\section{Conclusion}

The management of patients with PCC and PGL remains a challenge for anaesthesia. Preoperative preparation of volume status and treatment with $\alpha$ 
and $\beta$ blocker is helpful for minimizing intra operative major complications due to excessive catecholamine release. Despite preparation, the second surgery was associated with varying intraoperative haemodynamic lability; factors like large tumour size, prolonged duration of anaesthesia, tumour handling, and excess catecholamine release directly affect the prognosis.

\section{References}

1. Lenders JW, Eisenhofer G, Manneli M, Pacak K. Pheochromocytoma. The Lancet 2005; 366: 665-75. https://doi.org/10.1016/S0140-6736(05)67139-5

2. Golden SH, Robinson KA, Saldanha I, Anton B, Ladenson PW. Prevalence and incidence of Endocrine and Metabolic Disorders in the United States: A comprehensive review. J ClinEndocrinolMetab2009;94:1853-1878. https://doi.org/10.1210/jc.2008-2291

3. Myklejord DJ. Undiagnosed Pheochromocytoma: The Anesthesiologist Nightmare. Clinical Medicine andResearch2004;2(1):59-62.

https://doi.org/10.3121/cmr.2.1.59

PMid:15931336 PMCid:PMC1069072

4. Baraka A, Siddik S, Jalbout M, Yaacoub C. Variable hemodynamic fluctuations during resection of multicentricextraadrenalpheochromocytomas. Can JournAnesth2002;49(7):682-88.

https://doi.org/10.1007/BF03017445

PMid:12193485

5. Lenders et al. Pheochromocytoma and Paraganglioma: An Endocrine Society Clinical Practice Guideline. J ClinEndocrinolMetab 2014; 99:1915-1942.

https://doi.org/10.1210/jc.2014-1498

6. Lenders JW, Pacak K, Walther MM et al. Biochemical diagnosis of Pheochromocytoma: which test is best? JAMA 2002; 287: 1427-1434. https://doi.org/10.1001/jama.287.11.1427

7. Timmers HJ, Pacak K et al. Biochemically Silent Abdominal Paragangliomas in Patients with Mutations in the Succinate Dehydrogenase Subunit B Gene. J ClinEndocrinolMetab 2008; 93: 48264832.

https://doi.org/10.1210/jc.2008-1093

PMCid:PMC2626451

8. Kinney MAO, Warner ME, van Heerden JA et al. Perianesthetic Risks and Outcomes of Pheochromocytoma and Paraganglioma Resection. AnesthAnalg2000;91:1118-1123.

PMid:11049893 